\title{
A "Bio-Basics" Short Course: Bringing Modern Biology to An Engineering Faculty
}

\author{
James D. Sweeney ${ }^{1}$, Lokesh Joshi ${ }^{1,3}$, Alyssa Panitch ${ }^{1,3}$, Edward Hall ${ }^{2}$ \\ Harrington Department of Bioengineering ${ }^{1}$, and \\ Office of Engineering Research Services ${ }^{2}$, \\ The I.A. Fulton School of Engineering, and \\ The Biodesign Institute ${ }^{3}$ \\ Arizona State University, Tempe, AZ
}

\section{Introduction}

In our post-genomic world, engineers (including engineering faculties!) increasingly need at least a working knowledge of biology and the life sciences. The Arizona State University faculty short course "Bio-Basics" has cycled through two consecutive semester offerings in 2004. This course has provided a structure and forum for interested faculty in ASU's I.A. Fulton School of Engineering to participate in a series of class meetings focused on a range of topics in modern biology. In each of its first two offerings at ASU, the Bio-Basics short course has capped out its enrollment at its desired maximum of forty participants per semester. This paper describes the objectives, design, implementation, as well as initial and ongoing assessment and evaluation of the Bio-Basics faculty short course.

\section{Short Course Objectives}

The Fulton School at ASU has committed its strategic planning to a range of use-inspired research themes (e.g. human health, communication systems, nanotechnology, electronics and biomaterials, human-machine interfaces, remote sensing and autonomous networks, applied mathematics) which span not only the traditional engineering science underpinnings in chemistry and physics but also the life sciences. In order to assist engineering faculty to jump-start their currency of knowledge in biology, a team of Bioengineering faculty has implemented this short course.

This effort is particularly timely at ASU, as at many other universities, as new, large-scale research efforts are emphasized that seek to integrate faculties in engineering, the physical, and the life and medical sciences into effective transdisciplinary teams. The recently created Biodesign Institute $^{1}$ at ASU, for example, brings together experts in engineering, biotechnology, biomedicine, nanotechnology, information technology and cognitive science to foster fundamental improvements in human health and quality of life. Nationally, the Batelle technology forecast for the year 2020 also clearly indicates that the traditional lines between the physical, life and medical sciences will become increasingly blurred. Predicted strategic 
technological trends include: genetic based medical and health care, green integrated technology, omnipresent computing including implanted systems, nanomachines, designer foods and crops, intelligent goods and appliances, and the development of "super senses" using sensors and electronic or genetic technologies. ${ }^{2}$ In the 2004 annual technology opinion survey of IEEE Fellows, $72 \%$ of respondents listed biomolecular engineering as the field that will have the "biggest social impact" over the next 10 years. ${ }^{3}$ The National Academy of Engineering also has included biotechnology within its projected core knowledge set for the "2020 Engineer."4 In recognition of these trends a one-semester 'Biology for Engineers' course is now in development at ASU that will become a required component of the undergraduate curriculum for all engineers training either at the I.A. Fulton School on the main Tempe Campus as well as for those at the polytechnic-oriented East Campus.

It is within this landscape that the dual objectives of this faculty short course have been identified. These are to (i) provide participants with foundational knowledge and perspective across a spectrum of topics in biological systems, while also (ii) promoting opportunities to form new research connections and collaborations between engineering, life sciences and physical sciences faculty members.

\section{Short Course Design and Implementation}

The course was designed around a ten-week schedule, avoiding overlap with the beginning and concluding sections of a fifteen-week semester calendar. Meetings were once a week for an hour and fifteen minutes and were centered on an interactive lecture of about forty to sixty minutes with time for questions, answers and open discussion. Three of the authors of this paper (Sweeney, Joshi and Panitch) served as course organizers, facilitators and speakers. The fourth author (Hall) directs the Office of Engineering Research Services, which has provided financial and logistical support for the course. A number of additional guest speakers for the course were recruited from the faculties of ASU's School of Life Sciences, the Biodesign Institute at ASU, as well as from the Translational Genomics Institute (TGen) in Phoenix. Guest lecturers were asked to provide a blend of tutorial level information on a focused topic, along with an overview of the potential for research collaborations or opportunities in their field.

The course was advertised in advance primarily by an open email invitation to the Fulton School faculty and enrollment was limited to a maximum of forty participants per session. The course was offered free of cost to the faculty including receipt of a copy of the background information text for the course, Aydin Tözeren and Stephen Byers' New Biology for Engineers and Computer Scientists. ${ }^{5}$ Internet resources such as the National Library of Medicine's PubMed "Bookshelf"6 also were promoted to participants as a no-expense means to peruse greater depth textbook readings in biomedicine and biology. A course Blackboard ${ }^{\circledR}$ web-site was used to post information for participants (e.g. announcements, schedule, lecture PowerPoint ${ }^{\circledR}$ files, internet links, further reading, etc.).

Course content was chosen on the assumption that participants would have had little or no recent exposure to basic concepts and knowledge in modern biology. Topics covered in the two course offerings (not all topics included in each semester) included: 
- Course Introduction with Brief Overview of Modern Biology

- Genomics and Molecular Evolution

- Microbial Functional Genomics

- Proteomics: Proteins and Peptides as Pharmaceuticals

- De Novo Protein Design and Protein Engineering

- Metabolic Pathway Engineering

- Photosynthesis and Protein Complexes

- The Immune System and Immune Engineering

- Applied Immunology and Epidemiology

- Biological Molecular Motors

- Membrane Biophysics and Cell Excitability

- Developmental Biology

- Overall Convergence of Biology, Medicine, Engineering and Computing

\section{Assessment and Evaluation}

Participants in the short course were drawn from faculty of all ranks (including the tenured and tenure-track faculty plus teaching and research faculty) and from all engineering and computer science units of the Fulton School, as well as from mathematics, physics, and life sciences. Overall, $42 \%$ of participants were full Professors, 15\% Associate Professors and 20\% Assistant Professors, with $23 \%$ holding other non-tenure teaching, research or staff positions. The majority of participants (55\%) were drawn from Computer Systems Engineering, Computer Science and from Electrical Engineering.

An anonymous survey $(\mathrm{N}=24$ responses) was conducted early in the second offering of the short course in order to better understand participants' pre-existing knowledge of biology and life sciences, and their use of biology in current research and collaborations. Participant expectations for the course and their ratings of the relative importance of biology in the training of engineers were also surveyed. Confirming the belief that most participants would have little or no current background in the course content, $75 \%$ rated their prior knowledge of biology and the life sciences at the high school level (with $8 \%$ having had some undergraduate coursework, $13 \%$ significant undergraduate and/or graduate coursework, and $4 \%$ rating themselves as an expert). Fifty per cent of survey respondents rated their use of biology or any other life science prior to the short course in research or collaborations as "none" (33\% as a "small amount," $8 \%$ as "medium," and $8 \%$ as "high"). The two most common survey responses to the open-ended question "Why are you interested in this course?" were to enhance the potential for new research topics and collaborations, and to gain basic knowledge (either broadly or in specific areas). Respondents described a range of topics in response to the question "What are the one or two topics in biology that you want to learn more about?" Most commonly, topics in genetics and in fundamental areas of cell biology were listed. Respondents appear to have entered the short course with an existing predisposition to rate the importance of biology and the life sciences highly. In addressing the question "How do you rate the relative importance of knowledge and skills in biology and the life sciences in the training of young engineers?" $95 \%$ of respondents answered, "As important as chemistry and physics" or higher. 
It is our conclusion that this short course has been highly successful for those faculty members who dedicated themselves to regular participation. Long-term tracking of course participant productivity in biological or biomedical research areas and/or involving new collaboration(s) with life scientists (in comparison to the Fulton School faculty overall) has been initiated with the expectation that participants will in the long-term be better positioned for success in such efforts.

\section{References}

1. For on-line information on this transdisciplinary effort see: http://www.biodesign.org/.

2. Batelle Technology Forecasts: Strategic Technologies for 2020. Available on-line at: http://www.battelle.org/forecasts/technology2020.stm.

3. “Technology Trends 2004," IEEE Spectrum., pp. 8-13, January, 2004. Available on-line at: http://www.spectrum.ieee.org/WEBONLY/resource/jan04/0104fell.html.

4. National Academy of Engineering. The Engineer of 2020: Visions of Engineering in the New Century, 118 pages, 2004. Available on-line at: http://books.nap.edu/catalog/10999.html?onpi newsdoc05172003.

5. Tözeren, A., Byers, S.W. New Biology for Engineers and Computer Scientists. Pearson Prentice Hall, 286 pages, 2004.

6. Available on-line at: http://www.ncbi.nlm.nih.gov/entrez/query.fcgi?db=Books.

\section{Acknowledgements}

The authors wish to acknowledge the efforts of the many guest lecturers who have contributed their time and energies to making the Bio-Basics Short Course a success. These include: Colleen Brophy, Yung Chang, Wayne Frasch, Giovanna Ghirlanda, Bert Jacobs, Sudhir Kumar, George Poste, Jeffrey Touchman, Vim Vermaas, Jeanne Wilson-Rawls, and Neal Woodbury.

\section{Biographical Information}

JAMES SWEENEY is an Associate Professor of Bioengineering at Arizona State University. He received his Ph.D. and M.S. degrees in Biomedical Engineering from Case Western Reserve U. in 1988 and 1983, respectively, and his Sc.B. Engineering degree (Biomedical Engineering) from Brown U. in 1979. He is currently Director of the Flinn Foundation funded Multi- and Interdisciplinary Graduate Training Program in Bioengineering at ASU.

LOKESH JOSHI is an Associate Professor of Bioengineering at Arizona State University. He received his Ph.D. in Biology and Biochemistry at the University of Bath in 1994. He received his B.S. in Chemistry and Biology as well as an M.S. in Zoology from the University of Rajasthan in 1987 and 1989, respectively. He is Acting Director of the Center for Protein and Peptide Therapeutics within the Biodesign Institute at ASU.

ALYSSA PANITCH is an Assistant Professor of Bioengineering at Arizona State University. She received her Ph.D. degree in Polymer Science and Engineering from the University of Massachusetts in Amherst in 1997 and her B.A. in Biochemistry from Smith College and B.S. in Chemical Engineering from the University of Massachusetts in Amherst both in 1990. She is also a member of the Biodesign Institute's Center for Protein and Peptide Therapeutics.

EDWARD HALL is the Executive Associate Dean for Research in the I.A. Fulton School of Engineering at Arizona State University. He received his Ph.D. in Materials Science from Northwestern University in 1970. He joined Motorola the same year and was with them 31 years holding both research and research management positions. In 2002 he joined Arizona State University as a research faculty member and then in 2004 assumed his current administrative position in the Office of Engineering Research Services. 